\title{
Contribution of ocean overturning circulation to tropical rainfall peak in the Northern Hemisphere
}

\author{
Dargan M. W. Frierson ${ }^{1 \star}$, Yen-Ting Hwang ${ }^{1}$, Neven S. Fučkar ${ }^{2,3}$, Richard Seager ${ }^{4}$, Sarah M. Kang ${ }^{5}$, \\ Aaron Donohoe ${ }^{6}$, Elizabeth A. Maroon ${ }^{1}$, Xiaojuan Liu ${ }^{1}$ and David S. Battisti ${ }^{1}$
}

\begin{abstract}
Rainfall in the tropics is largely focused in a narrow zonal band near the Equator, known as the intertropical convergence zone. On average, substantially more rain falls just north of the Equator'. This hemispheric asymmetry in tropical rainfall has been attributed to hemispheric asymmetries in ocean temperature induced by tropical landmasses. However, the ocean meridional overturning circulation also redistributes energy, by carrying heat northwards across the Equator. Here, we use satellite observations of the Earth's energy budget ${ }^{2}$, atmospheric reanalyses ${ }^{3}$ and global climate model simulations to study tropical rainfall using a global energetic framework. We show that the meridional overturning circulation contributes significantly to the hemispheric asymmetry in tropical rainfall by transporting heat from the Southern Hemisphere to the Northern Hemisphere, and thereby pushing the tropical rain band north. This northward shift in tropical precipitation is seen in global climate model simulations when ocean heat transport is included, regardless of whether continents are present or not. If the strength of the meridional overturning circulation is reduced in the future as a result of global warming, as has been suggested ${ }^{4}$, precipitation patterns in the tropics could change, with potential societal consequences.
\end{abstract}

One of the defining features of the Earth's climate is the fact that tropical rainfall primarily maximizes within the Northern Hemisphere (Fig. 1a,b). This is especially evident in the Atlantic and eastern Pacific oceans, where precipitation near $5^{\circ} \mathrm{S}$ is much weaker than at the equivalent locations north of the Equator, which are some of the rainiest regions on Earth in the intertropical convergence zone. Throughout the tropics, societies as diverse as subsistence farmers in the Sahel and the technology-based cities of India are reliant, directly or indirectly, on monsoon rains. How tropical rainfall evolves in the future will have important and widespread social consequences.

Precipitation in the tropics exists largely within narrow zonal bands owing to the large-scale atmospheric overturning known as the Hadley circulation ${ }^{5}$. Within the lower branch of this circulation, the trade winds converge near the Equator, drying the subtropics and bringing moisture into the rain bands. This circulation is thermally direct, and thus transports energy in the directions of its upper branch. The Hadley circulation also plays a primary role in determining the hemispheric asymmetry of tropical precipitation because it transports copious amounts of moisture from the Southern Hemisphere to the Northern Hemisphere. A northward cross-equatorial mass transport in the moist lower branch of the circulation performs the moisture transport, and is compensated aloft by a dry, southward cross-equatorial flow ${ }^{6}$.

Several recent studies ${ }^{7-9}$ have argued that a useful attribution of the hemispheric asymmetry of tropical precipitation can be performed with an examination of the hemispheric asymmetry of the atmospheric energy budget. Tropical precipitation responds to atmospheric heating even from well outside the tropics by shifting towards the heat input ${ }^{7-14}$. The influence of an extratropical heat source is spread by baroclinic eddies into the tropics, where the Hadley circulation responds with a cross-equatorial component. The anomalous Hadley circulation causes an energy transport away from the hemisphere with stronger atmospheric heating and a moisture transport towards the heating. On the basis of this energetic framework, we perform an attribution of the observed energy input into the atmosphere at the top-of-atmosphere (TOA) and surface, and claim that whatever causes the heating of the Northern Hemisphere atmosphere to be larger is also what causes precipitation to maximize in the Northern Hemisphere tropics.

Despite large differences in land coverage and cloudiness between the hemispheres, much of the globe receives nearly identical net TOA radiative input at a given latitude in both the Northern Hemisphere and Southern Hemisphere (Fig. 2a). However, when averaged over the hemispheres, the Southern Hemisphere receives $1.5 \mathrm{~W} \mathrm{~m}^{-2}$ more radiation than the Northern Hemisphere, primarily owing to the area between $17^{\circ}$ and $35^{\circ}$ latitude, with an additional contribution from the polar cap. A map of TOA net radiation (Fig. 2b) shows that the Northern Hemisphere receives less radiation in the critical region of $17^{\circ}-35^{\circ}$ because the Sahara and Arabian deserts are a strong net sink of TOA radiation. Owing to their high albedo, these deserts are the only substantial regions between $30^{\circ} \mathrm{N}$ and $30^{\circ} \mathrm{S}$ that lose energy through radiation, a fact that was inferred in 1969 by the Nimbus III team. The polar cap in the Southern Hemisphere receives more net radiation than the Northern Hemisphere cap owing to the low temperature and low outgoing longwave radiation over Antarctica. The hemispheric difference in radiation can be alternatively partitioned into a similar net shortwave irradiance in each hemisphere, and a larger longwave flux out of the warmer Northern Hemisphere ${ }^{15}$.

As the Southern Hemisphere receives slightly more net radiation than the Northern Hemisphere, TOA radiation cannot be the cause of the present-day maximum of tropical rainfall north of the Equator. If there is a larger energy flux into the Northern Hemisphere atmosphere than the Southern Hemisphere atmosphere, it must instead be caused by a northward cross-equatorial ocean heat

\footnotetext{
'Department of Atmospheric Sciences, University of Washington, Seattle 98195, USA, ${ }^{2}$ International Pacific Research Center, University of Hawaii, Honolulu 96822, USA, ${ }^{3}$ Institut Català de Ciències del Clima, Barcelona 08005, Spain, ${ }^{4}$ Lamont-Doherty Earth Observatory of Columbia University, Palisades, New York 10964, USA, ${ }^{5}$ School of Urban and Environmental Engineering, Ulsan National Institute of Science and Technology, 689-798, Korea, ${ }^{6}$ Department of Earth, Atmospheric, and Planetary Sciences, Massachusetts Institute of Technology, Cambridge, Massachusetts 02139, USA. *e-mail:dargan@atmos.washington.edu
} 
a

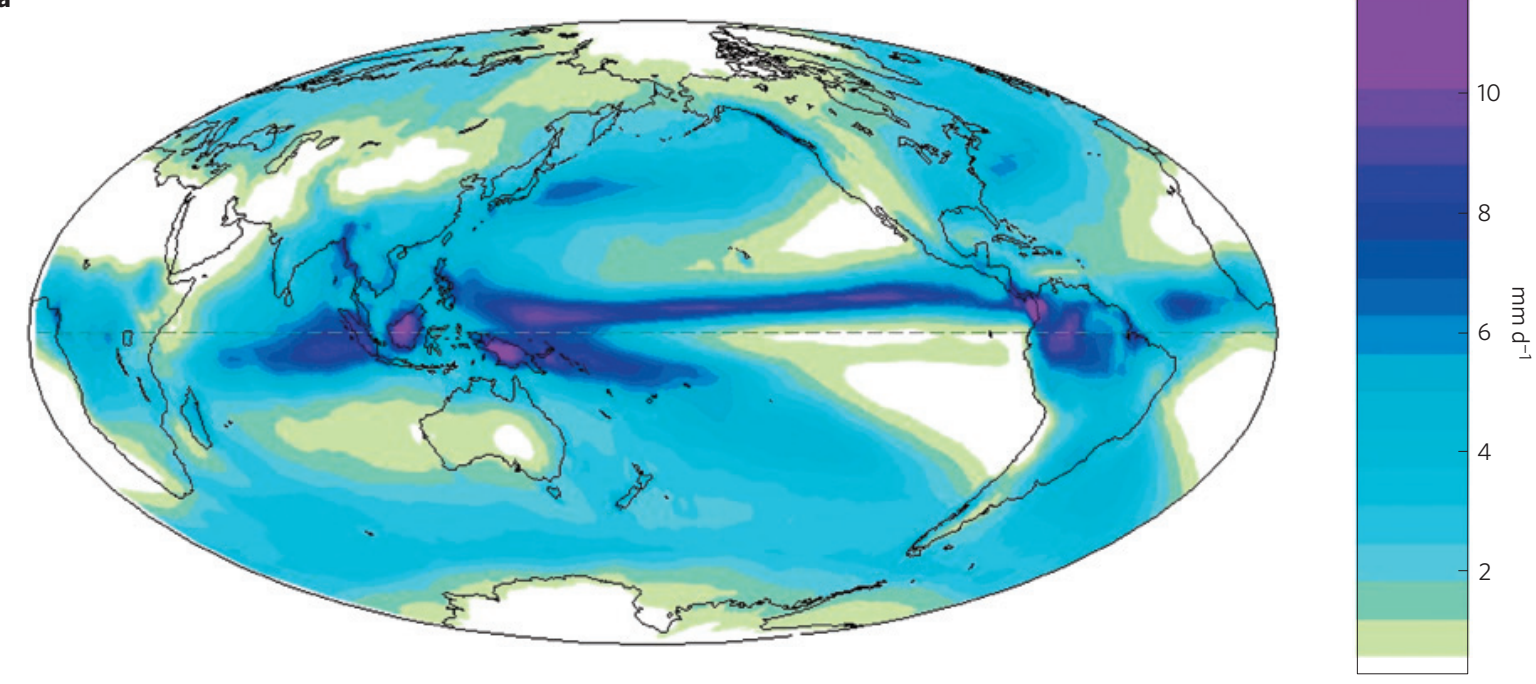

b

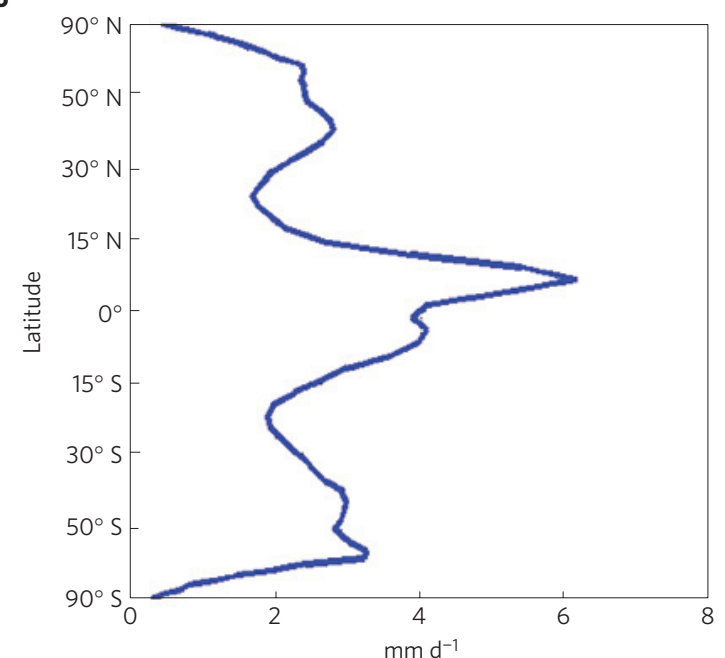

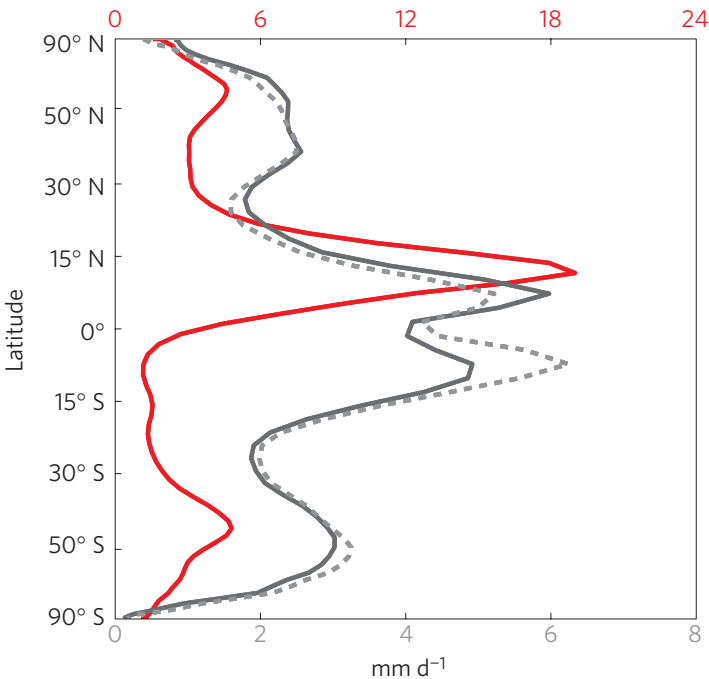

Figure 1 | Observed and modelled annual mean precipitation. a, Annual mean precipitation, 2001-2010 from the Global Precipitation Climatology Project Version 2.1 (ref. 1). b, Zonal average of a. c, Zonal mean precipitation from an aquaplanet GCM simulation using the GFDL AM2.1 model with prescribed surface heat fluxes from observations (red), and the realistic geography ECHAM GCM using observed (solid grey) and hemispherically symmetrized surface heat fluxes (dashed grey). The simulated tropical rainfall in the aquaplanet simulation maximizes at approximately $11^{\circ} \mathrm{N}$, whereas in observations the peak is at approximately $5^{\circ} \mathrm{N}$.

transport (OHT), and fluxed into the atmosphere at the surface. This is because, in the time mean, whereas the net surface flux over land is zero, over ocean it is balanced by the divergence of OHT.

OHT can be estimated from satellite observations and atmospheric reanalyses ${ }^{3}$. The deduced zonally averaged Northern Hemisphere ocean to atmosphere surface heat flux substantially exceeds the Southern Hemisphere equivalent at nearly every latitude poleward of $20^{\circ}$ (Fig. 2c,d). On average, the Northern Hemisphere atmosphere receives $3.1 \mathrm{~W} \mathrm{~m}^{-2}$ more upward energy flux from the surface than the Southern Hemisphere corresponding to a northward cross-equatorial OHT of 0.4 PW (Table 1). The latitudes in which the Northern Hemisphere surface flux exceeds the Southern Hemisphere by the most are regions of the Gulf Stream and Kuroshio currents $\left(25-40^{\circ} \mathrm{N}\right)$, and also the latitudes between $45^{\circ}$ and $70^{\circ}$ that encompass regions of deep water production in the North Atlantic and wind-driven upwelling in the Southern Ocean. In the deep tropics a region exists where the Northern Hemisphere flux is larger, owing to upwelling differences between the hemispheres.
The northward cross-equatorial oceanic heat transport occurs in the Atlantic (Supplementary Fig. S1), where the surface heat flux has a striking hemispheric asymmetry in the extratropics. The meridional overturning circulation (MOC) facilitates the northward cross-equatorial heat transport in the Atlantic, connecting deep water production in the Nordic Seas and subpolar North Atlantic and upwelling in the Southern Ocean ${ }^{16,17}$.

Simulations of the present climate from Coupled Model Intercomparison Project Phase 5 (CMIP5; 20 models) and Phase 3 (CMIP3; 15 models) all have a larger climatological surface heat flux into the Northern Hemisphere atmosphere than into the Southern Hemisphere atmosphere as well (Supplementary Table S1), providing further evidence that a northward crossequatorial OHT is a fundamental aspect of our present climate. The hemispheric asymmetry of TOA radiation is less robust in CMIP3/5; biases in extratropical clouds often lead to excessive heating of the Southern Hemisphere, and thus to the southward intensification of tropical precipitation that characterizes the double inter-tropical convergence zone problem ${ }^{8}$. In some models, the TOA radiation 
a

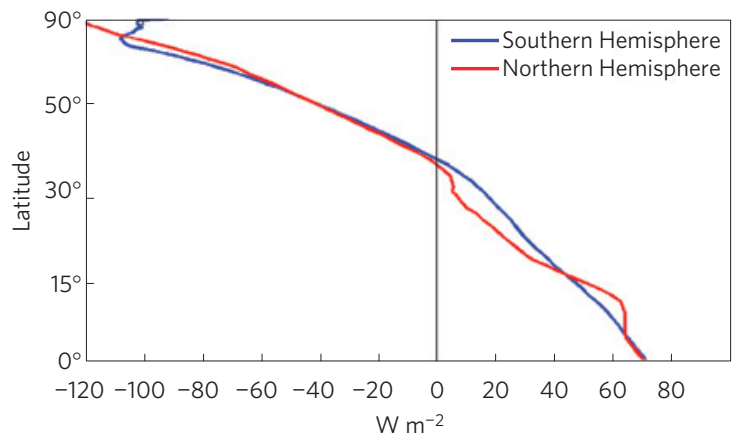

b

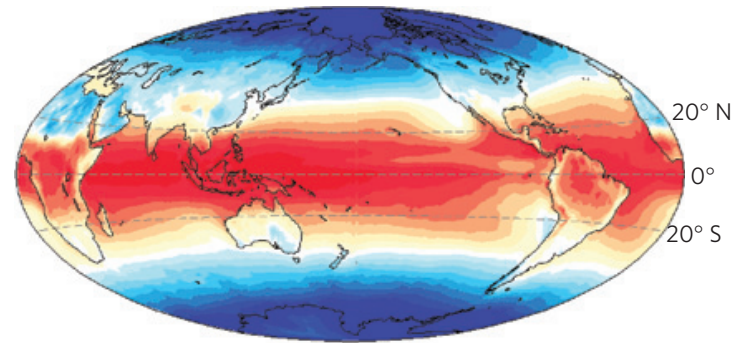

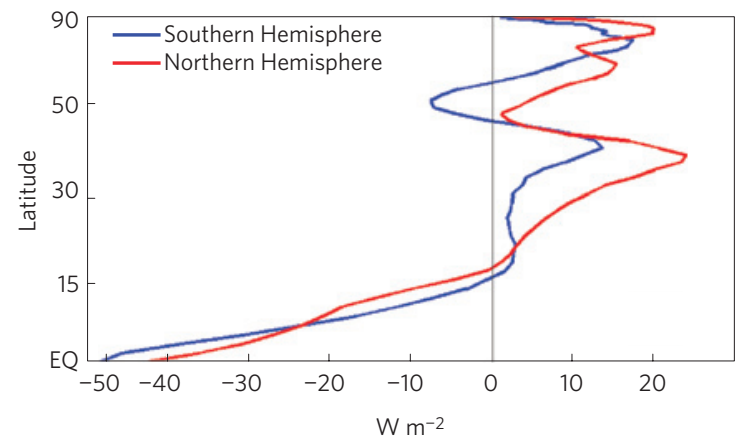

d

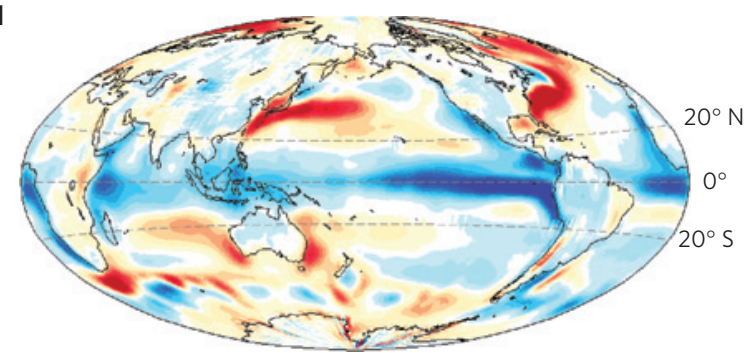

\begin{tabular}{ccccccccc}
\hline-80 & -60 & -40 & -20 & 1 & 1 & 1 & 1 & 1 \\
$W^{-2} m^{-2}$ & 20 & 40 & 60 & 80
\end{tabular}

Figure 2 | Observed net TOA radiation and surface energy fluxes. a, Zonal average TOA net downward radiation in the Northern Hemisphere and Southern Hemisphere from CERES EBAF, 2001-2010 (ref. 2). b. Latitude-longitude structure of a. c, Zonal average of the net surface flux (ocean to atmosphere) in the Northern Hemisphere and Southern Hemisphere from CERES EBAF TOA net radiation minus ERA-Interim atmospheric transports, 2001-2010 (ref. 3). d, Latitude-longitude structure of $\mathbf{c}$.

Table 1 | The hemispheric asymmetry (Northern Hemisphere minus Southern Hemisphere) of energy flux into the atmosphere and its implied magnitude of cross-equatorial energy transport.

\begin{tabular}{|c|c|c|c|c|c|c|}
\hline & \multicolumn{2}{|c|}{ 10-year mean } & \multicolumn{2}{|c|}{ Range } & \multicolumn{2}{|c|}{ Standard deviation } \\
\hline & $\begin{array}{l}\text { Hemispheric } \\
\text { asymmetry } \\
\left(\mathrm{W} \mathrm{m}^{-2}\right)\end{array}$ & $\begin{array}{l}\text { Implied cross-EQ } \\
\text { transport (PW) }\end{array}$ & $\begin{array}{l}\text { Hemispheric } \\
\text { asymmetry } \\
\left(\mathrm{W} \mathrm{m}^{-2}\right)\end{array}$ & $\begin{array}{l}\text { Implied cross-EQ } \\
\text { transport (PW) }\end{array}$ & $\begin{array}{l}\text { Hemispheric } \\
\text { asymmetry } \\
\left(\mathrm{W} \mathrm{m}^{-2}\right)\end{array}$ & $\begin{array}{l}\text { Implied cross-EQ } \\
\text { transport (PW) }\end{array}$ \\
\hline Downward TOA flux & -1.5 & -0.2 & -1.9 to -1.0 & -0.2 to -0.1 & 0.4 & 0.05 \\
\hline Upward surface flux & 3.1 & 0.4 & 2.4 to 3.8 & 0.3 to 0.5 & 0.7 & 0.09 \\
\hline
\end{tabular}

The upward surface plus downward TOA implied transport value corresponds to a southward atmospheric transport. The range and standard deviation are calculated using annual means. Cross-EQ, cross-equatorial.

biases can even overwhelm the northward cross-equatorial ocean transport, leading to a Southern Hemisphere maximum of zonally averaged tropical precipitation.

We argue that the structure of the oceanic MOC causes tropical precipitation to maximize in the Northern Hemisphere, by the following mechanism, illustrated in Fig. 3. The Northern Hemisphere ocean releases heat to the extratropical atmosphere, which is compensated for by a lesser atmospheric heat transport from the subtropics to the extratropics in the Northern Hemisphere than in the Southern Hemisphere. The hemispheric difference between the atmospheric transport is especially striking between $20^{\circ}$ and $50^{\circ}$ latitude, where the Southern Hemisphere transports around 0.5 PW more energy poleward than the Northern Hemisphere (Supplementary Fig. S2). The atmosphere therefore moves less heat poleward from the Northern Hemisphere lower latitudes than from the Southern Hemisphere lower latitudes. The tropical mean circulation responds by transporting energy from the Northern Hemisphere to the Southern Hemisphere. The southward energy transport is accomplished by a northerly crossequatorial flow in the upper branch and an accompanying southerly cross-equatorial flow in the lower branch, which also transports moisture northward, resulting in the Northern Hemisphere peak of tropical precipitation.

An aquaplanet global climate model (GCM) simulation forced with the observed surface heat flux has tropical precipitation peaking clearly within the Northern Hemisphere, at a higher latitude than the observed rain band (Fig. 1c). This simulation shows that the OHT is more than sufficient to explain the northern peak in zonal mean precipitation. To show that OHT is also necessary to produce a Northern Hemisphere tropical maximum, we use a GCM with full continental geometry and the observed surface flux distribution (Fig. 1c). When the surface flux in this GCM is symmetrized between hemispheres, the precipitation becomes much larger in the Southern Hemisphere tropics than in the Northern Hemisphere (Fig. 1c). These simulations support our conclusions from observations, that TOA radiation effects 


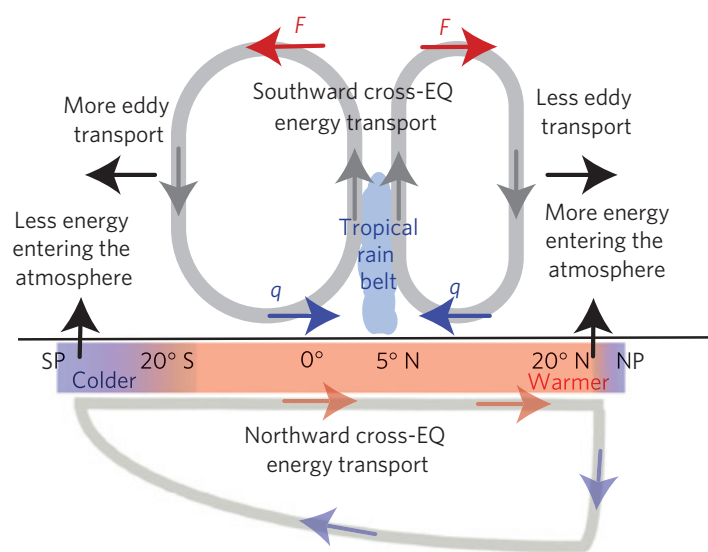

Figure 3 | Schematic of the role of the oceanic MOC in forcing the Northern Hemisphere maximum of tropical precipitation. Heat is released from the ocean to the atmosphere in the Northern Hemisphere owing to cross-equatorial OHT. The atmosphere responds through eddy energy transports in the extratropics, and a cross-equatorial Hadley circulation, which fluxes energy from the Northern Hemisphere to the Southern Hemisphere. The moisture transport by the Hadley circulation is in the opposite direction as the energy transport, so tropical precipitation moves northwards. SP, South Pole; NP, North Pole; cross-EQ, cross-equatorial; $q$, moisture transport; $F$, energy transport.

(along with the possible influence of land) would cause a Southern Hemisphere rainfall maximum, and the observed OHT is a primary cause of the Northern Hemisphere maximum.

Our simulations are from atmosphere-only GCMs, and there is the potential for a rich interplay among ocean dynamics, land properties and TOA radiation, which should be studied in detail. For instance, Earth's continental configuration plays an important role in setting the direction and strength of the oceanic MOC. A recent idealized coupled GCM study ${ }^{14}$ showed that opening a Southern Hemisphere Drake Passage-like channel anchors deep water production and the tropical rain band in the Northern Hemisphere, explicitly supporting a MOC-determined tropical rain band location within a coupled context. This result has since been shown in an aquaplanet coupled GCM setting ${ }^{18}$. These and other coupled interactions should be further examined in comprehensive GCMs and observations.

Our argument by no means precludes the existence of strong local influences on tropical precipitation. Many well-documented local mechanisms shape the east-west asymmetries of rainfall, the seasonal cycle and interannual variability, and seek to explain the Northern Hemisphere peak in tropical rain through tropical processes and continental/topographic features ${ }^{19-21}$. Indeed, in our comprehensive model simulations with symmetrized OHT, whereas the Pacific and Atlantic intertropical convergence zones clearly shift into the Southern Hemisphere, the Indian Ocean rainfall location is affected much less (Supplementary Fig. S5), indicating the primary role of local processes within that basin. The links between coupled tropical and tropical-extratropical dynamics and global energetics should be investigated further as well.

This study on what controls the present tropical precipitation position has strong implications for our understanding of past and future climates. Much palaeoclimate literature focuses on the possibility of changes in the MOC structure and strength. This analysis suggests that such changes would be associated with latitudinal shifts in tropical precipitation. Previous studies with GCMs have shown that MOC slowdowns are indeed accompanied by southward shifts in rainfall over much of the tropics ${ }^{11}$.

The role of TOA radiation was also probably different in past climates. For instance, the Sahara Desert was green in the mid-Holocene ${ }^{22}$, which could on its own cause the Northern Hemisphere to receive more radiation than the Southern Hemisphere, and shift tropical rainfall further into the Northern Hemisphere, unless other terms such as clouds could compensate. In contrast, in glacial climates when ice covered much of the Northern Hemisphere, the albedo effect would probably reduce Northern Hemisphere net radiation and push tropical precipitation southward ${ }^{11}$, although reduced outgoing longwave radiation over ice sheets would have a compensating effect.

In the future, owing to global warming, we expect reductions in the strength of the oceanic MOC (ref. 4), accompanied by changes in surface albedo, clouds, aerosols and ocean heat uptake, presenting a complex challenge for GCM forecasts of tropical precipitation $^{7,23}$. The complexity of the task is matched by the importance to tropical societies of determining what will, in fact, happen. The analysis of the coupling between energy fluxes, circulation and precipitation presented here provides a useful paradigm for addressing this critical global problem.

\section{Methods}

A 10-year mean of the Clouds and the Earth's Radiant Energy System (CERES) Energy Balanced and Filled (EBAF) satellite product ${ }^{2}$ from 2001 to 2010 is used to study TOA energetics, which includes contributions from downward solar radiation, upward solar radiation (determined by the distribution of the planetary albedo) and outgoing longwave radiation (determined primarily by the temperature, greenhouse gas concentration, and cloudiness of each column).

Surface heat fluxes are not routinely measured at the ocean surface. The most accurate method to derive the net surface heat flux is, therefore, an indirect one, subtracting atmospheric energy transport estimates based on reanalysis data from TOA satellite observations of net radiative flux. We estimate the implied OHT using the method of ref. 24 applied to the recently released ERA-Interim data $\operatorname{set}^{3}$ over $^{2}$ the same time period as the CERES data (2001-2010). Although this new reanalysis data set is thought to be a significant improvement over previous estimates, there of course remains some uncertainty in any such energy budget estimate. A basic physical expectation can be used to infer the sign of the cross-equatorial OHT without reference to reanalyses; an assumption of thermal directness of the deep tropical overturning, along with the larger TOA flux into the Southern Hemisphere, requires a northward cross-equatorial OHT.

An aquaplanet (ocean-covered) version of the Geophysical Fluid Dynamics Laboratory (GFDL) AM2.1 atmospheric GCM (ref. 25) forced with the observed surface heat flux (Fig. 2d) into the oceanic mixed layer is integrated to demonstrate that the observed surface heat flux is more than sufficient to shift the maximum of zonal mean tropical precipitation to its observed location in the Northern Hemisphere. The ECHAM GCM version 4.6 with realistic geography is additionally used, forced with the observed surface flux distribution in the control case. The symmetrized case with the ECHAM GCM uses a surface flux distribution that is zonally symmetric, with values chosen at each latitude such that the zonal integral of the surface flux is equal to the average between the Northern Hemisphere and Southern Hemisphere zonal integrals of the observed surface flux.

Received 3 May 2013; accepted 13 September 2013; published online 20 October 2013

\section{References}

1. Huffman, G. J., Adler, R. F., Bolvin, D. T. \& Gu, G. Improving the global precipitation record: GPCP Version 2.1. Geophys. Res. Lett. 36, L17808 (2009).

2. Wielicki, B. A. et al. Clouds and the Earth's radiant energy system (CERES): An Earth observing system experiment. Bull. Am. Meteorol. Soc. 77, 853-868 (1996).

3. Dee, D. P. et al. The ERA-Interim reanalysis: Configuration and performance of the data assimilation system. Q. J. R. Meteorol. Soc. 137, 553-597 (2011).

4. Weaver, A. J. et al. Stability of the Atlantic meridional overturning circulation: A model intercomparison. Geophys. Res. Lett. 39, L20709 (2012).

5. Hadley, G. Concerning the cause of the general trade winds. Phil. Trans. R. Soc 29, 58-62 (1735).

6. Dima, I. M. \& Wallace, J. M. On the seasonality of the Hadley Cell. J. Atmos. Sci. 60, 1522-1527 (2003).

7. Frierson, D. M. W. \& Hwang, Y-T. Extratropical influence on ITCZ shifts in slab ocean simulation of global warming. J. Clim. 25, 720-733 (2012).

8. Hwang, Y-T. \& Frierson, D. M. W. A new look at the double ITCZ problem: Connections to cloud bias over the Southern Ocean. Proc. Natl Acad. Sci. USA 110, 4935-4940 (2013).

9. Hwang, Y-T., Frierson, D. M. W. \& Kang, S. M. Anthropogenic sulfate aerosol and the southward shift of tropical precipitation in the 20th century. Geophys. Res. Lett. 40, 1-6 (2013). 
10. Chiang, J. C. H. \& Bitz, C. M. Influence of high latitude ice cover on the marine Intertropical Convergence Zone. Clim. Dynam. 25, 477-496 (2005).

11. Zhang, R. \& Delworth, T. L. Simulated tropical response to a substantial weakening of the Atlantic thermohaline circulation. J. Clim. 18, 1853-1860 (2005).

12. Kang, S. M., Held, I. M., Frierson, D. M. W \& Zhao, M. The response of the ITCZ to extratropical thermal forcing: Idealized slab-ocean experiments with a GCM. J. Clim. 21, 3521-3532 (2008).

13. Yoshimori, M. \& Broccoli, A. J. On the link between Hadley circulation changes and radiative feedback processes. Geophys. Res. Lett. 36, L20703 (2009).

14. Fučkar, N. S., Xie, S-P., Farneti, R., Maroon, E. A. \& Frierson, D. M. W. Influence of the extratropical ocean circulation on the intertropical convergence zone in an idealized coupled general circulation model. J. Clim. 26, 4612-4629 (2013).

15. Voigt, A., Stevens, B., Bader, J. \& Mauritsen, T. The observed hemispheric symmetry in reflected shortwave irradiance. J. Clim. 26, 468-477 (2013).

16. Marshall, J. \& Speer, K. Closure of the meridional overturning circulation through Southern Ocean upwelling. Nature Geosci. 5, 171-180 (2012).

17. Lumpkin, R. \& Speer, K. Global ocean meridional overturning. J. Phys. Oceanogr. 37, 2550-2562 (2007).

18. Marshall, J., Donohoe, A., Ferreira, D. \& McGee, D. The role of the ocean circulation in setting the mean position of the ITCZ. Clim. Dyn. http://dx.doi.org/10.1007/s00382-013-1767-z (2013).

19. Song, X. \& Zhang, G. J. Convection parameterization, tropical Pacific double ITCZ, and upper ocean biases in the NCAR CCSM3. Part II: Coupled feedback and the role of ocean heat transport. J. Clim. 23, 800-812 (2010).

20. Xie, S-P. \& Philander, S. G. H. A coupled ocean-atmosphere model of relevance to the ITCZ in the eastern Pacific. Tellus 46A, 340-350 (1994).

21. Takahashi, K. \& Battisti, D. S. Processes controlling the mean tropical pacific precipitation pattern. part I: The Andes and the eastern Pacific ITCZ. J. Clim. 20, 3434-3451 (2007).

22. DeMenocal, P. B et al. Abrupt onset and termination of the African Humid Period: Rapid climate response to gradual insolation forcing. Quat. Sci. Rev. 19, 347-361 (2000).

23. IPCC Climate Change 2007: The Physical Science Basis (eds Solomon, S. et al.) (Cambridge Univ. Press, 2007).

24. Trenberth, K. E. \& Fasullo, J. T. An observational estimate of ocean energy divergence. J. Phys. Oceanogr. 38, 984-999 (2008).
25. Anderson, J. L. et al. The new GFDL global atmosphere and land model AM2-LM2: Evaluation with prescribed SST simulations. J. Clim. 17, 4641-4673 (2004).

\section{Acknowledgements}

We acknowledge helpful conversations with L. Thompson, C. Bitz, K. Armour, B. Rose, I. Held, R. Pierrehumbert, D. Hartmann, J. Scheff and M. Wallace. J. Fasullo provided the ERA-Interim energy transports. We acknowledge the Program for Climate Model Diagnosis and Intercomparison and the WCRP's Working Group on Coupled Modelling for their roles in making available the CMIP3 and CMIP5 data sets. D.M.W.F. and Y-T.H. are supported by NSF Grants AGS-0846641 and AGS-0936069, and a University of Washington Royalty Research Fund grant. N.S.F. is supported by the Japan Agency for Marine-Earth Science and Technology (JAMSTEC), by NASA through grant No. NNX07AG53G, and by NOAA through grant No. NA11NMF4320128, which sponsor research at the International Pacific Research Center. R.S. is supported by NSF award AGS-0804107. S.M.K. is supported by the Basic Science Research Program through the National Research Foundation of Korea (NRF) funded by the Ministry of Science, ICT and Future Planning (2013R1A1A3004589). A.D. is supported by the NOAA Climate and Global Change Fellowship, administered by the University Corporation for Atmospheric Research. E.A.M. is supported by the National Defense Science and Engineering Graduate Fellowship Program.

\section{Author contributions}

D.M.W.F., N.S.F. and Y-T.H. designed the original diagnostics and experiments, with frequent subsequent input on diagnostic techniques and experimental design from all co-authors. Y-T.H. and D.M.W.F. analysed the observations. Y-T.H. performed experiments with the GFDL model. X.L. and D.S.B. designed experiments with the ECHAM model, and X.L. ran the ECHAM model experiments. D.M.W.F. led the writing of the paper, with substantial input from all co-authors.

\section{Additional information}

Supplementary information is available in the online version of the paper. Reprints and permissions information is available online at www.nature.com/reprints. Correspondence and requests for materials should be addressed to D.M.W.F.

\section{Competing financial interests}

The authors declare no competing financial interests. 